\title{
O Desempenho Motor de Crianças com Paralisia Cerebral
}

\section{Jacqueline Maria Resende Silveira Leite}

Fisioterapeuta, doutoranda do programa de Medicina Interna e Terapêutica, disciplina de Medicina de Urgência e Profa. Mestre do curso de Fisioterapia do Centro Universitário de Lavras - UNILAVRAS, Lavras-MG, Brasil.

A definição mais adotada pelos especialistas é de 1964 e caracteriza a paralisia cerebral (PC) como "um distúrbio permanente, embora não invariável, do movimento e da postura, devido a defeito ou lesão não progressiva do cérebro no começo da vida"'.

A encefalopatia crônica não progressiva da infância, originalmente conhecida como paralisia cerebral (PC), é atribuída a lesôes não progressivas ocorridas no desenvolvimento do cérebro durante o período fetal ou do lactente. Os distúrbios motores da paralisia cerebral são frequentemente acompanhados por alteraçóes sensoriais, perceptuais, cognitivas, de comunicação, comportamento, epilepsia e por problemas musculoesqueléticos secundários ${ }^{2-4}$.

A PC pode ser classificada por dois critérios: pelo tipo de disfunção motora presente, ou seja, o quadro clínico resultante, que inclui os tipos extrapiramidal ou discinético (atetóide, coreico e distônico), atáxico, misto e espástico; e pela topografia dos prejuízos, ou seja, localização do corpo afetado, que inclui tetraplegia ou quadriplegia, monoplegia, paraplegia ou diplegia e hemiplegia. $\mathrm{Na}$ PC, a forma espástica é a mais encontrada e freqüente em $88 \%$ dos casos ${ }^{1}$.

Diante dos diferentes quadros clínicos observados, diversas modalidades de tratamentos objetivam promover saúde, independência funcional e, sobretudo, qualidade de vida a crianças com $\mathrm{PC}^{5,6}$.

Toda criança com PC precisa ser assistida por uma equipe multiprofissional, e esta equipe tem que estar coesa em prol de um desenvolvimento motor o mais adequado possível.

As crianças com PC apresentam dificuldade no processamento das informaçôes necessárias para a aquisição de uma habilidade motora, além de fatores musculoesqueléticos como: fraqueza muscular, alterações no tono muscular e/ou a diminuição da amplitude de movimento, tornando-se importante uma melhor investigação quanto ao grau de comprometimento de cada criança. Isto torna o aprendizado de habilidades motoras específicas mais difícil quando comparado as crianças sem alteraçóes neuromotoras ${ }^{7}$. Contudo, com a intervenção adequada o sistema nervoso pode se reorganizar, sendo uma propriedade do sistema nervoso, onde todas as formas e mecanismos para estimular e/ou ativar as habilidades motoras são conhecidas como plasticidade. Portanto, a atividade realizada nas terapias (fisioterapia, terapia ocupacional, fonoaudiologia, estimulação visual, entre outras) torna-se um fator crucial para aperfeiçoar a recuperação, ou seja, mesmo com uma lesão no Sistema Nervoso Central é possível aprender e reter as informaçōes aprendidas.

A PC pode apresentar diversos problemas nas atividades funcionais, no controle dos movimentos voluntários, prejudicando suas capacidades diárias, bem como sobrecarregar cuidadores e terapeutas ${ }^{8}$.

As informações referentes às limitações são queixas principais de crianças, pais e familiares, assim a avaliação do desempenho funcional destas crianças possibilita aos profissionais de saúde fundamentar sua prática terapêutica e orientar seus cuidadores?

É de grande importância estimular e incentivar a criança PC a realizar suas habilidades motoras tanto no ambiente terapêutico, quanto familiar, independente do quadro topográfico, e estes estímulos devem ser inseridos precocemente.

A maioria dos cuidadores e/ou responsáveis apresenta uma dificuldade em lidar com a criança PC por vários motivos, entre eles destacam-se a não aceitação da patologia, a opiniáo de que com o tempo tudo passa e ela irá melhorar, a concepção religiosa ou a postura negativista que admite que as intervençóes são inefetivas, pois toda 
criança com PC apresenta retardo mental e nunca será independente. É possível enumerar outros tantos preconceitos, mas o que devemos ter em mente é que a criança com PC tem uma capacidade imensa de se recuperar e de adquirir habilidades motoras e funcionais que a farão feliz para viver da sua maneira.

Sendo assim, quanto antes as crianças com PC receberem intervençóes apropriadas, mais rapidamente conseguirão melhorar suas atividades motoras e serem mais independentes e autoconfiantes.

\section{REFERÊNCIAS}

1.Leite JMRS, Prado GF. Paralisia cerebral: aspectos fisioterapêuticos e clínicos. Rev Neurocienc 2004;12(1):41-5.

http://dx.doi.org/10.4181/RNC.2004.12.41

2.Morris C. Definition and classification of cerebral palsy: a historical perspective. Dev Med Child Neurol 2007;49(S109);3-7. http://dx.doi.org/10.1111/j.1469-8749.2007.tb12609.x

3.Rosenbaum P, Paneth N, Leviton A, Goldstein M, Bax M. A report: the definition and classification of cerebral palsy. Dev Med Child Neurol 2007;49(11):1357-68.

4.Rethlefsen SA, Ryan DD, Kay R. Classification Systems in CP. Orthopedic Clin of North America 2010;41:457-67.

http://dx.doi.org/10.1016/j.ocl.2010.06.005

5.Scazufca M. Brazilian version of the Burden Interview scale for the assessment of burden of care in carrers of people with mental illnesses. Rev Bras Psiquiatr 2002;24(1):12-7.

http://dx.doi.org/10.1590/S1516-44462002000100006

6.Palisano R, Rosenbaum P, Walter S, Russell D, Wood E, Galuppi B. Deve-lopment and reliability of a system to classify gross motor function in children with cerebral palsy. Dev Med Child Neurol 1997;39(4):214-23.

http://dx.doi.org/10.1111/j.1469-8749.1997.tb07414.x

7.Ekman LL. Neurociência: Fundamentos para a Reabilitaçâo. Editora Guanabara Koogan, 2000, 347p.

8.Cunha JOV, Rézio GS, Formiga CKMR. Correlação entre Assistência do Cuidador e Desempenho Funcional em Crianças com Paralisia Cerebral. Rev Neurocienc 2012:20(4):534-540.

http://dx.doi.org/10.4181/RNC.2012.20.762.7p

9.Silva FPP, Gomes CNM, Gil KVC, Da Matta DSP. Comparação do Desempenho Funcional de Crianças com Paralisia Cerebral Diparéticas e Hemiparéticas. Rev Neurocienc 2012:20(4):511-516.

http://dx.doi.org/10.4181/RNC.2012.20.725.6p 